\title{
A Retrospective Case-control Study on a Triad of Risk Predictors Associated With Periodontitis; a Regression Analysis
}

\section{DR. HINA MAHMOOD}

Islamabad Medical and Dental College

DR. SEHAR NAEEM ( $\square$ sehar.naeem@iideas.edu.pk)

Islamabad Medical and Dental College

DR. UZMA SAEED

Islamabad Medical and Dental College

DR. BATOOL ZARA

Foundation University Medical College

\section{Research Article}

Keywords: Periodontitis, Education, Dental care, Case-control study

Posted Date: May 7th, 2021

DOI: https://doi.org/10.21203/rs.3.rs-476561/v1

License: (c) (i) This work is licensed under a Creative Commons Attribution 4.0 International License. Read Full License 


\section{A Retrospective case-control study on a triad of risk predictors associated with periodontitis; A Regression Analysis}

DR. HINA MAHMOOD

Assistant Professor and Head of department Periodontology, Islamabad Medical and Dental College, Dental Section, Barahkahu, Islamabad, Pakistan

\section{DR. SEHAR NAEEM (Corresponding Author)}

Post Graduate Trainee periodontology department, Islamabad Medical and Dental College, Dental Section, Islamabad, Pakistan

House number 54, Street number 4, Block DD, PWD housing society, Islamabad

Postal code: 45710

sehar.naeem@iideas.edu.pk

$051-2232045$

Mobile \# 0333-0226614

DR. UZMA SAEED

Post graduate Trainee periodontology department, Islamabad Dental Hospital Barahkahu, Islamabad, Pakistan

\section{DR. BATOOL ZARA}

Assistant Professor and Head of department Periodontology, Foundation University Medical College, Pakistan 


\section{ABSTRACT}

AIMS: This case-control study was conducted to analyze the association of periodontitis with risk predictors i.e. education status, brushing habits and past dental visits in systemically healthy patients.

MATERIALS AND METHODS: A total of 1097 systemically healthy, non-tobacco using patients with age $\geq 18$ years who reported to periodontology department were included. The demographic details and dental care pattern of the patients were extracted from the records of periodontology department and their frequencies were formulated. The association of three predicting factors i.e. education status, brushing habits and past dental visits was assessed on SPSS using binary logistic regression analysis.

RESULTS: A total of $471(42.9 \%)$ patients were diagnosed with periodontitis. Higher frequency of periodontitis was observed in patients who were male and $>50$ years of age. Subjects with $\geq 12$ years of education, regular brushing habits and regular past dental visits showed greater odds of being safe from periodontitis.

CONCLUSIONS: A positive association between the study variables and periodontitis was observed, which will help the clinicians in prediction of periodontitis in systemically healthy, non-smoking individuals. It also indicates a need of tailor made dental educational and awareness programs for prevention and control of periodontitis in systemically healthy individuals.

\section{KEYWORDS:}

Periodontitis, Education, Dental care, Case-control study 


\section{INTRODUCTION:}

Periodontitis is a disease of the supporting tissues of the teeth, characterized as irreversible polymicrobial breakdown of host homeostasis resulting in a progressive destruction of periodontium supporting the teeth. ${ }^{1}$

The prevalence of periodontal diseases has been reported in many studies worldwide which varies depending upon the criteria being used and the diversity in population being studied. ${ }^{2}$ Data from epidemiological studies revealed that Periodontitis is the sixth most prevalent chronic condition in the world. ${ }^{3}$ Globally, about $11 \%$ of individuals, are suffering with severe type of periodontitis. ${ }^{4}$ In Pakistan, according to $\mathrm{WHO}, 18 \%$ of the population suffers from periodontitis out of which $31 \%$ has advanced periodontitis. ${ }^{5}$

Periodontitis is a multifactorial disease. Adverse effects of factors like, smoking, diabetes, and stress on periodontal health have been reported widely all around the world as well as in Pakistan and their link is well established. ${ }^{6}$ Furthermore, lower education level results in inadequate oral health knowledge, insufficient dental preventive behaviors, and less usage of oral health services. ${ }^{7}$ A higher prevalence of periodontitis among subjects with low education has also been reported. ${ }^{8}$ Inadequate oral hygiene practice also plays significant role on plaque accumulation and development of periodontal disease.${ }^{9}$ Regular dental visits are also considered a critical factor for the success in prevention as well as controlling periodontitis and maintaining a functional dentition. ${ }^{10}$ Therefore, relation between education status, brushing habits and past dental visits with periodontitis in otherwise healthy individuals need to be established. The objective of this study was to find out the relationship between these three factors on presence of periodontitis, so that tailor made educational and awareness programmes can be designed for prevention and control of periodontitis.

\section{METHODOLOGY:}

This case-control study was conducted in periodontology department of Islamabad Dental Hospital (IDH) after approval from institutional review board of Islamabad Medical and Dental College (dental section). All methods were performed according to the guidelines of Helsinki declaration (2008). 
Record files of 4490 patients were retrieved from periodontology department for the year 2018 from $1^{\text {st }}$ January to $31^{\text {st }}$ December. Records of 1097 patients who were systemically healthy, $\geq 18$ years of age and had no history of tobacco use were selected according to the inclusion criteria. Data was extracted from the records by exploring dental history, education status, oral hygiene practice and past dental visits.

Age of the patients was divided into 3 groups i.e. $18-35 y$ years, $36-50$ years and $>50$ years. Using the periodontal examination charts from records, patients with pocket depth greater than $3 \mathrm{~mm}$ were diagnosed with periodontitis. ${ }^{11}$ Patient's education status was divided into 2 groups i.e. patients with years of education $<12$ and patients with years of education $\geq 12 .{ }^{9}$ Brushing habits of the patient was divided into 2 groups i.e. regular and irregular brushers. Those who brushed their teeth occasionally were included in the irregular brushers category and those who brushed once or twice daily were included in regular brushers category. ${ }^{12}$ Past dental history of the patients was divided into 3 groups i.e. those who visit once in a year (regular attendee), those who visit only when they encounter a dental problem (irregular dental attendee) and those who never visited a dentist before. ${ }^{13}$

This data was entered in statistical package for social sciences (SPSS) software version 22. The periodontal diagnosis of the patients was noted and their frequencies were formulated. The effects of study variables i.e. education status, brushing habits and past dental visits on periodontitis were studied by applying binary logistics regression method using hosmer-lemeshow goodness-of-fit ${ }^{14}$, Wald's statistics and odd's ratio (with $95 \%$ confidence interval limit). A p-value of $\leq 0.05$ was considered statistically significant.

\section{RESULTS:}

This retrospective case-control study included 1097 patients (table I). Maximum patients i.e. 638 (58.2\%) were 18-35 years old (table I). Socio-demographic details with dental care pattern of the patients are given in table I. 
VARIABLES

\begin{tabular}{|c|c|}
\hline \multicolumn{2}{|l|}{ AGE } \\
\hline $18-35$ & $638(58.2)$ \\
\hline $36-50$ & 350 (31.9) \\
\hline$>50$ & $109(9.9)$ \\
\hline \multicolumn{2}{|l|}{ GENDER } \\
\hline Male & $468(42.7)$ \\
\hline Female & $629(57.3)$ \\
\hline \multicolumn{2}{|l|}{ MARITAL STATUS } \\
\hline Un-married & $347(31.6)$ \\
\hline Married & $750(68.4)$ \\
\hline \multicolumn{2}{|l|}{ EDUCATION } \\
\hline$<12$ years of education & $727(66.3)$ \\
\hline$\geq 12$ years of education & $370(33.7)$ \\
\hline \multicolumn{2}{|l|}{ BRUSHING HABITS } \\
\hline Irregular & $228(20.8)$ \\
\hline Regular & 869 (79.2) \\
\hline \multicolumn{2}{|l|}{ PAST DENTAL VISITS } \\
\hline Never visited before & $495(45.1)$ \\
\hline Irregular & $468(42.7)$ \\
\hline Regular & $134(12.2)$ \\
\hline
\end{tabular}




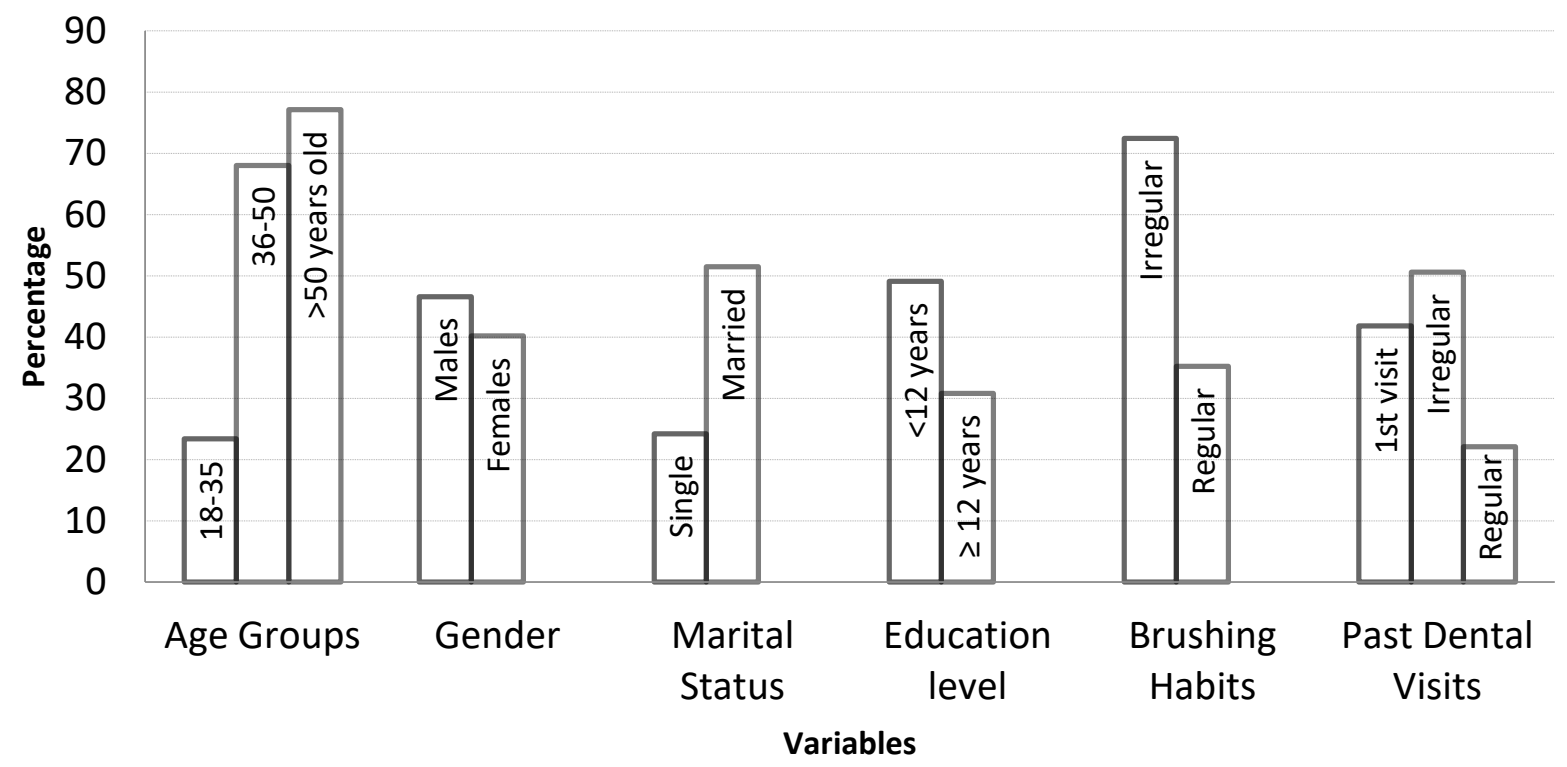

\section{Fig 1: Demographic data and dental care pattern of patients suffering from periodontitis}

Bar chart (fig. 1) is representing different risk factors on the x-axis and percentages within the factors on $y$ axis. Greater frequency of periodontitis was seen in $>50$ years of age $(n=84,77.1 \%)$, males $(n=218,46.6 \%)$, married $(n=385,51.3 \%)$, with < than 12 years of education $(n=357,49.1 \%)$, irregular brushers $(n=165$, $72.4 \%)$ as well as patients with history of irregular past dental visits $(n=239,51.1 \%)$.

\begin{tabular}{llll} 
Variables & Wald's statistics & Significance & Exp (B) \\
\hline Education status & 11.662 & .001 & 1.633 \\
\hline Brushing habits & 64.301 & .000 & 3.871 \\
\hline Never visited before & 31.344 & .000 & \\
\hline Irregular visitors & 6.855 & .009 & .700 \\
Regular visitors & 16.863 & .000 & 2.975
\end{tabular}

TABLE II: Forward stepwise binary logistics regression analysis using periodontitis as dependent variable

Binary logistic regression was used to predict the probability of having periodontitis for a given person based on three predictors i.e. education status, brushing habits and past dental visits. The overall percentage of correct decision increased from $57 \%$ to $66.6 \%$ explaining that the model correctly classifies $66 \%$ of the 
patients with the inclusion of study variables as predictors. Hosmer-lemeshow test showed insignificant results ( $p$ value 0.576 ) indicating the model fits the data very well.

Values of Walds's statistic and Odd's ratio of the variables is shown in table II.

\section{DISCUSSION:}

This study reports the frequency and risk indicators of periodontitis among the patients reporting to IDH. Of all patients, 471 (42.9\%) were diagnosed with periodontitis. Similar prevalence was reported in dental institutes of Rawalpindi and Multan with $34.5 \%$ and $48.49 \%$ patients respectively. ${ }^{5,15}$ On the contrary, prevalence of periodontitis reported by Haq MW, in patients having systemic illness was higher (92\%) as compared to the present results. ${ }^{16}$

Periodontitis predilection was seen in male and elderly population as reported by systematic review. ${ }^{17}$ Wald's statistics was applied to find the association of periodontitis with the study variables (i.e. education status, brushing habits and past dental visits) which showed significant results ( $p$ value $<0.05$ ) indicating that the factors are contributing equally to the prediction of occurrence of periodontitis (table II).

Regression analysis showed 1.6 times lesser chance of developing periodontitis in patients with $\geq 12$ years of education (table II). This significant result is in contrast with the results reported from Multan, where an insignificant relation was reported between education status and dental disease. ${ }^{15}$ The conflict might be because of different categorization criteria of education status used. However, a study conducted in North Jordan reported a strong association between low level of education and increased prevalence of periodontitis. There is 5.5 times more chance of having periodontitis in patients with low education level which supports the results of present study. ${ }^{9}$ Higher prevalence of periodontitis among subjects with low education has also been reported in Thailand and USA. ${ }^{8,18}$

It was further seen that patients who brush their teeth once daily (regular brushers) have 3.8 times lesser odds of getting periodontitis than patients who don't brush their teeth regularly (table II). This result is consistent with another study from Rawalpindi and Sweden which reports a significant correlation of regular brushing habits with better periodontal health. ${ }^{5,19} \mathrm{~A}$ meta- analysis reported $34 \%$ lower odds of periodontitis in patients brushing regularly supporting the aforementioned results. ${ }^{20}$ 
Regularity of dental visits was observed to be significantly associated with decreased prevalence of periodontitis in this study. Patients who visit regularly at least once in a year had 2.9 times lesser risk of getting periodontitis than those who never visited before. Unfortunately, there is dearth of local evidence regarding correlation of dental visits with periodontitis but internationally, this correlation has been investigated. A meta-analysis reported that subjects who regularly visited dentists at least once a year had $44 \%$ lower risk of periodontitis than those who did not. ${ }^{20}$ Also researches from New York, North Jordan and Brazil are in agreement with current findings. ${ }^{9,10,17}$

\section{CONCLUSION:}

The present study provides valuable information on important modifiable risk factors of periodontitis which need to be addressed during the management as well as prediction of periodontitis.

Brushing habits, education status and past dental visits were significantly related to periodontal health. Given the negative effects of lower education status, irregular brushing habits and dental visits on periodontal health, these factors can no longer be ignored.

Prediction of periodontitis can be done by using this data, in healthy individuals reporting to clinics with lower education status, irregular brushing habits and dental visits so that they can be protected from this chronic disease.

Tailor made awareness programmes and regular periodontal evaluation is impediment for prevention and control of periodontitis, since it is a chronic, painless and slow-progressing inflammatory disease and can be detected earlier and successfully controlled through regular periodontal examinations.

\section{LIMITATION:}

It should be noted that because this study was conducted on a group of patients referred to a periodontal department for treatment, the results are not likely to reflect the characteristics of whole population. Further large-scale, community-based studies are required to develop effective public health policies.

\section{REFERENCES:}

1. Al Qahtani NA, Joseph B, Deepthi A, Vijayakumari BK. Prevalence of chronic periodontitis and its risk determinants among female patients in the Aseer Region of KSA. J Taibah Univ Sci. 2017;12(3):241-8 .

2. Slots J. Periodontitis: facts, fallacies and the future. Periodontol 2000. 2017;75(1):7-23. 
3. Eke PI, Wei L, Borgnakke WS, Thornton-Evans G, Zhang X, Lu H et al. Periodontitis prevalence in adults $\geq 65$ years of age, in the USA. Periodontol 2000. 2016;72(1):76-95.

4. Marcenes W, Kassebaum NJ, Bernabé E, Flaxman A, Naghavi M, Lopez A et al. Global burden of oral conditions in 1990-2010: a systematic analysis. J Dent Res. 2013;92(7):592-7.

5. Bokhari SA, Suhail AM, Malik AR, Imran MF. Periodontal disease status and associated risk factors in patients attending a Dental Teaching Hospital in Rawalpindi, Pakistan. JISP, 2015;19(6):678-85

6. Van Dyke TE, Dave S. Risk factors for periodontitis J Int Acad Periodontol. 2005;7(1): 3-7.

7. Wehmeyer MM, Corwin CL, Guthmiller JM, Lee JY. The impact of oral health literacy on periodontal health status. J Public Health Dent. 2014;74(1):80-87.

8. Torrungruang K, Tamsailom S, Rojanasomsith K, Sutdhibhisal S, Nisapakultorn K, Vanichjakvong O et al. Risk indicators of periodontal disease in older Thai adults. J Periodontol. 2005;76(4):55865.

9. Ababneh KT, Hwaij ZM, Khader YS. Prevalence and risk indicators of gingivitis and periodontitis in a Multi-Centre study in North Jordan: a cross sectional study. BMC Oral Health. 2012;12(1):1-8.

10. Oliveira Costa F, Miranda Cota LO, Pereira Lages EJ, Medeiros Lorentz TC, Soares Dutra Oliveira AM, Antônio Dutra Oliveira $P$ et al. Progression of periodontitis in a sample of regular and irregular compliers under maintenance therapy: a 3-year follow-up study. J Periodontol. 2011;82(9):1279-87.

11. Tonetti MS, Greenwell H, Kornman KS. Staging and grading of periodontitis: Framework and proposal of a new classification and case definition. J Periodontol. 2018;89(S1):149-61.

12. Lang NP, Cumming BR, Löe $\mathrm{H}$. Toothbrushing frequency as it relates to plaque development and gingival health. J Periodontol. 1973;44(7):396-405.

13. Yoshino K, Ito K, Kuroda M, Sugihara N. Tooth loss in problem-oriented, irregular, and regular attenders at dental offices. Bull Tokyo Dent Coll. 2016;57(1):11-9.

14. Fenlon C, O'Grady L, Doherty ML, Dunnion J. A discussion of calibration techniques for evaluating binary and categorical predictive models. Prev Vet Med. 2018;149(1):107-14. 
15. Amin M, Amanullah BM, Tarar AM. Dental Caries, Periodontal Disease and their associated factors among patients visiting dental teaching hospital in Multan, Pakistan. JPDA. 2016;25(3):99102.

16. Haq MW, Tanwir F, Tabassum S, Nawaz M, Siddiqui MF. Association of periodontitis and systemic diseases. Int J Dent Oral Health. 2015;1(1):1-7.

17. Natto ZS, Abu Ahmad RH, Alsharif LT, Alrowithi HF, Alsini DA, Salih HA et al. Chronic Periodontitis Case Definitions and Confounders in Periodontal Research: A Systematic Assessment. Biomed Res Int. 2018;2018.

18. Borrell LN, Burt BA, Warren RC, Neighbors HW. The role of individual and neighborhood social factors on periodontitis: the third National Health and Nutrition Examination Survey. J periodontol. 2006;77(3):444-53.

19. Axelsson $P$, Nyström B, Lindhe J. The long-term effect of a plaque control program on tooth mortality, caries and periodontal disease in adults: results after 30 years of maintenance. $\mathrm{J}$ clinic periodontol. 2004;31(9):749-57.

20. Lertpimonchai A, Rattanasiri S, Arj-Ong Vallibhakara S, Attia J, Thakkinstian A. The association between oral hygiene and periodontitis: a systematic review and meta-analysis. Int Dent J. 2017;67(6):332-43.

\section{DECLARATIONS:}

\section{Ethics approval and consent to participate:}

The study was approved by institutional review board of Islamabad Medical and Dental College (dental section). All methods were performed in accordance to Declaration of Helsinki (2008). Informed consent was obtained from all the participants that their personal data will be used for research purpose.

\section{Consent for publication:}

Consent was signed from every patient on our institution's consent form.

\section{Availability of data and materials:}


The datasets used and analyzed during the current study will be available from corresponding author on reasonable request.

\section{Competing interests:}

The authors declare that they have no competing interests.

\section{Funding:}

This research did not receive any specific grant from funding agencies in the public, commercial or nonprofit sectors.

\section{Author's Contributions:}

H.M. gave the concept and design. Did the revision, final approval and drafting.

S.N. did the drafting, analysis, interpretation and article writing.

U.S. did the drafting, data collection and revision.

B.Z. did the drafting, revision and editing.

Acknowledgements:

Not applicable.

\section{AUTHOR'S INFORMATION:}

- Affiliations:

Department of Periodontology, Islamabad Medical and Dental College, Dental Section, Barahkahu, Islamabad, Pakistan

H. Mahmood, S. Naeem and U. Saeed.

Department of Periodontology, Foundation University Medical College, Islamabad, Pakistan

B. Zara

- Corresponding author:

Correspondence to $\underline{\text { S. Naeem }}$. 

Figures

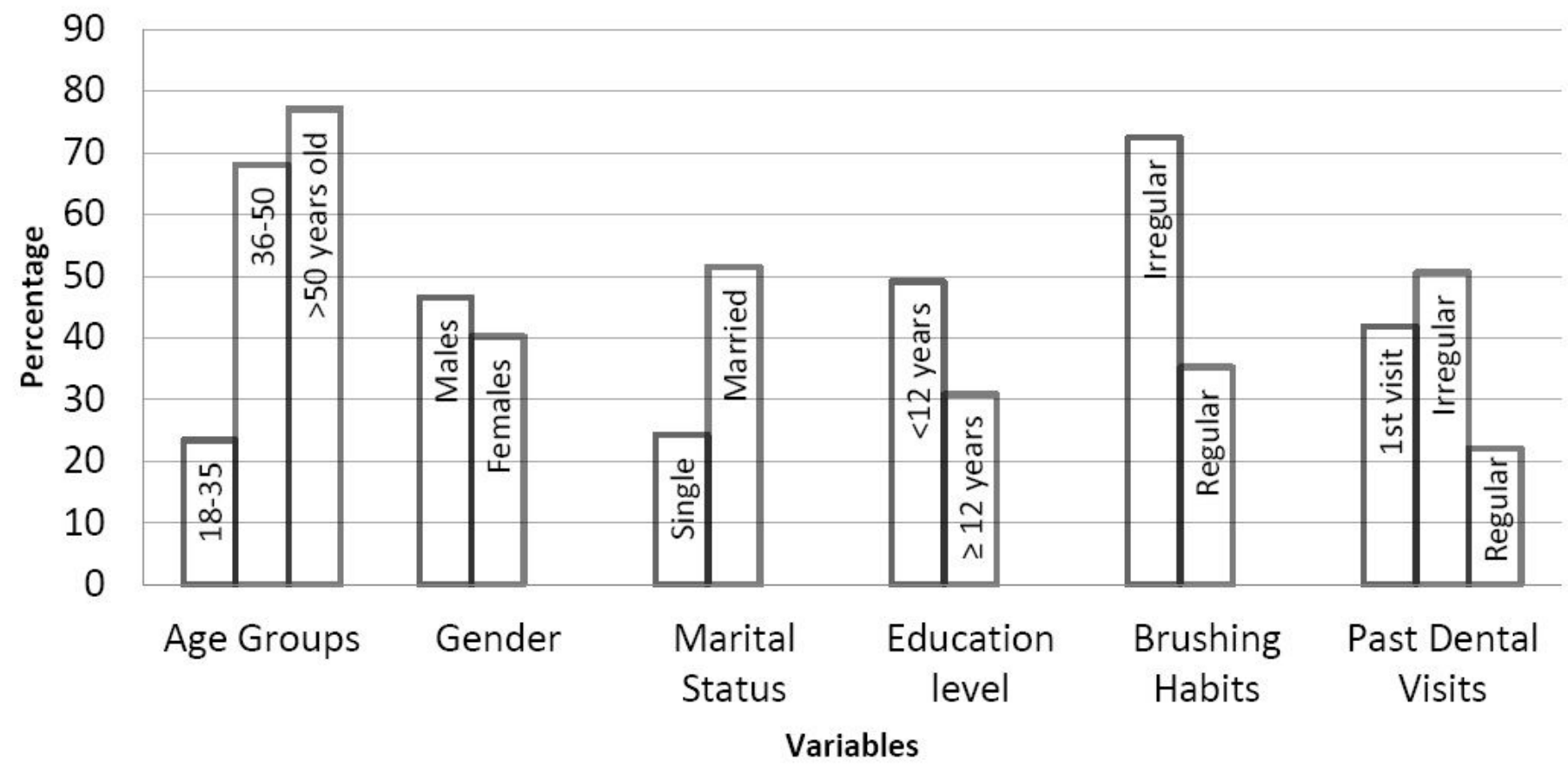

Figure 1

Demographic data and dental care pattern of patients suffering from periodontitis 